\title{
Pneumonia enzoótica em javalis (Sus scrofa) ${ }^{1}$
}

\author{
Roselene $\mathrm{Ecco}^{2 *}$, Andrea Maria Lazzari ${ }^{3}$ e Roberto M.C. Guedes ${ }^{2}$
}

\begin{abstract}
Ecco R., Lazzari M.A. \& Guedes R.M.C. 2009. [Enzootic pneumonia in wild boars (Sus scrofa).] Pneumonia enzoótica em javalis (Sus scrofa). Pesquisa Veterinária Brasileira 29(6):461-468. Departamento de Clinica e Cirurgia Veterinárias, Escola de Veterinária, Universidade Federal de Minas Gerais, Av. Antônio Carlos 6627, Cx. Postal 567, Belo Horizonte, MG 31270-901, Brazil. E-mail: ecco@vet.ufmg.br

The aim of this paper is to describe the clinical, epidemiological, pathological, bacteriological and immunohistochemical aspects of a pneumonia outbreak in a wild pig farm in the Distrito Federal, Brazil. Ninety wild pigs died in a period of five months, and 63 of these had pulmonary lesions. Clinically, the pigs presented reduced growth rate, anorexia, lethargy, cough and dyspnea, especially after they were moved. High body temperature $\left(40^{\circ} \mathrm{C}\right.$ in average) was verified in some animals. Auscultation revealed moderate pulmonary crepitation and stertors. Pulmonary gross lesions were typical of lobular bronchopneumonia. Lung lesions were characterized by ventral-cranial consolidation in the majority of the cases. The color of affected pulmonary areas varied from diffuse dark red to mosaic pattern (dark red lobule intercalate by grayish lobule) or diffusely grayish. The majority of the lungs had mucopurulent exsudate in the bronchial lumen that also drained from the parenchyma cut surface. Upon microscopy, the changes were characterized by purulent and histiocytic bronchopneumonia with necrotic foci. In some animals, there was BALT hyperplasia associated with perivascular and peribronchial plasma cells and lymphocytes infiltration in most of these cases. Bordetella bronchiseptica and Streptococcus spp. were the most frequently isolated bacteria. Immunohistochemistry evaluation demonstrated Mycoplasma hyopneumoniae on the luminal surface of bronchial and bronchiolar epithelial cells, and the DNA of bacteria was detected by PCR. This is the first report of bronchopneumonia in wild boars associated with $M$. hyopneumoniae infection.
\end{abstract}

INDEX TERMS: Wild pigs, bronchopneumonia, pathology, bacteriology, PCR, immunohistochemistry, Mycoplasma hyopneumoniae.

RESUMO.- O objetivo desse estudo foi descrever o quadro clínico e epidemiológico, os achados patológicos, bacteriológicos e imuno-histoquímicos de um surto de pneumonia em uma granja de Javalis do Distrito Federal, Brasil. Em um período de cinco meses, morreram 90 javalis. Desses, 63 tinham lesões pulmonares. Clinicamente apresentavam atraso no desenvolvimento corporal, diminui-

\footnotetext{
${ }^{1}$ Recebido em 5 de novembro de 2008.

Aceito para publicação em 24 de abril de 2009.

2 Departamento de Clinica e Cirurgia Veterinárias, Escola de Veterinária, Universidade Federal de Minas Gerais (UFMG), Av. Antônio Carlos 6627, Cx. Postal 567, Belo Horizonte, MG 31270-901, Brasil. "Autor para correspondência: ecco@vet.ufmg.br

3 União Pioneira da Integração Social (UPIS), SEP Sul 712/912, Conjunto A, Brasília, DF 70390-125, Brasil.
}

ção do apetite, letargia, tosse e dificuldade respiratória, principalmente quando movimentados. Constatou-se elevação da temperatura, $40^{\circ} \mathrm{C}$ em média. $\mathrm{Na}$ auscultação, havia crepitações e estertores pulmonares de intensidade moderada. As alterações macroscópicas nos pulmões analisados eram típicas de broncopneumonia lobular. As lesões caracterizavam-se por consolidação crânio-ventral na maioria dos pulmões. A coloração variava de difusamente vermelho-escuro a um padrão mosaico (lóbulos vermelho-escuros intercalados por lóbulos cinzas) ou difusamente acinzentados. Na maioria dos pulmões observou-se exsudato mucopurulento na luz dos brônquios e fluindo do parênquima. Histologicamente, as alterações eram de broncopneumonia purulenta e histiocitária com focos de necrose. Em alguns animais havia também hiperplasia do BALT e, na maioria dos animais, infiltração 
linfocítica perivascular e peribronquial. Bordetella bronchiseptica e Streptococcus spp. foram as principais bactérias isoladas. A imuno-histoquímica demonstrou a bactéria Mycoplasma hyopneumoniae no epitélio bronquiolar e bronquial e o DNA desta bactéria foi detectado pela PCR. Este é o primeiro relato de broncopneumonia em Javalis associado à infecção por $M$. hyopneumoniae.

TERMOS DE INDEXAÇÃO: Javalis, broncopneumonia, patologia, bacteriologia, PCR, imuno-histoquímica e Mycoplasma hyopneumoniae.

\section{INTRODUÇÃO}

A pneumonia é uma das doenças mais comuns dos suínos em países com criação intensiva (Liljegren et al. 2003). O aparelho respiratório é local freqüente para a entrada de patógenos, devido à constante exposição ao ambiente e troca gasosa. Um único patógeno pode causar doença, mas, não é incomum que múltiplos agentes estejam envolvidos (Brokmeier et al. 2008). A broncopneumonia em suínos é primariamente causada por bactérias tais como Mycoplasma spp., Pasteurella multocida e Actinobacillus pleuropneumoniae (Liljegren et al. 2003) e Actinobacillus suis (Taylor 2006).

A pneumonia enzoótica suína, causada primariamente pelo Mycoplasma hyopneumoniae, é uma doença respiratória crônica distribuída mundialmente, e pode afetar 70 a $100 \%$ dos animais em um rebanho de suínos (Kwon et al. 2002, Sarradel et al. 2003). Essa bactéria coloniza a superfície do epitélio respiratório resultando em diminuição e perda da atividade ciliar e degeneração das células epiteliais (Sarradel et al. 2003, Thacker 2004). A lesão característica da infecção é a hiperplasia do tecido linfóide associado aos brônquios (Opriessnig et al. 2004). Os sinais clínicos associados com a infecção por $M$. hyopneumoniae incluem tosse não produtiva, perda de peso e piora da conversão alimentar (Kwon et al. 2002, Caswell \& Williams 2007). Na Espanha, estudo sorológico para $M$. hyopneumoniae em amostras de javalis (Sus scrofa) resultaram negativas (Vicente et al. 2002). No Canadá, em um surto de infecção por circovirus tipo 2 em javalis, alguns animais apresentaram lesões pulmonares sugestivas de infecção por Mycoplasma spp. (Ellis et al. 2003). No Brasil, nos últimos anos, houve um crescimento na criação de javalis devido à demanda pelos consumidores por carnes exóticas, e consequentemente gerou um grande desafio sanitário, relacionado a doenças infecciosas. Em uma granja de javalis no Distrito Federal, Brasil, acompanhou-se os quadros clínico e epidemiológico, além dos achados patológicos, bacteriológicos e imunohistoquímicos de um surto de pneumonia que descrevemos neste artigo.

\section{MATERIAL E MÉTODOS}

Histórico do criatório. $O$ criatório possuía 500 javalis, incluindo reprodutores, filhotes e terminados. As fêmeas lactantes eram mantidas até o desmame em baias cobertas com piso cimentado. No desmame, que ocorria aos 60 dias de idade, os filhotes eram transferidos para piquetes sem cobertura vegetal. Aproximadamente aos 30 dias de idade os filhotes recebiam aplicação de ferro e vacina para pneumonia micoplásmica (dose única). A alimentação era a base de milho moído adicionado de núcleo e promotor de crescimento. Os terminados também eram suplementados com capim e abóbora. Em um período de 5 meses, de agosto de 2002 a janeiro de 2003, morreram 90 javalis. Desses, 63 tinham lesões pulmonares. Conforme informações dos criadores, nos 6 meses anteriores a esse período, houve outro surto em que a mortalidade foi de 100 animais. O início da mortalidade nesse criatório coincidiu com aquisição e introdução sem quarentena de reprodutores de uma criação que cruzava javalis machos com fêmeas suínas comerciais. Nessa propriedade a mortalidade era elevada segundo os criadores. A idade dos javalis clinicamente doentes e que posteriormente morreram, era de 30-120 dias de idade. Quatro animais morreram com 8 meses de idade. A mortalidade mais elevada ocorreu no desmame ou pós-desmame, quando os animais tinham 70-90 dias de idade. Nos dois surtos os animais foram medicados na ração com enrofloxacina ou oxitetraciclina. Alguns animais se recuperaram, porém evidenciaram grande redução no ganho de peso. O período dos surtos coincidiu com precárias condições de manejo. O solo do piquete onde os animais eram mantidos após o desmame era seco e com muita poeira. Além disso, algumas vezes os animais maiores e mais velhos de outros piquetes invadiam os piquetes dos mais jovens, provocando brigas.

Necropsia. Noventa javalis que morreram no período de julho de 2002 a janeiro de 2003 foram necropsiados. Destes, 63 animais foram incluídos nesse estudo. Do total de 90 javalis, somente sete foram necropsiados no mês de janeiro de 2003. À necropsia os pulmões foram avaliados macroscopicamente considerando a consistência, coloração, distribuição e aspecto das lesões. Amostras de cada lobo pulmonar e de todos os tecidos foram coletadas, fixadas em formol neutro $10 \%$ e processados rotineiramente para histopatologia.

Bacteriologia. Foram coletadas amostras do tecido pulmonar (geralmente de um dos lobos craniais) para análise microbiológica. As amostras foram semeadas em ágar sangue ovino $5 \%$ (AS) e ágar Mac Conkey (MC). As placas foram incubadas a $37^{\circ} \mathrm{C}$ por $24-48 \mathrm{~h}$. A identificação bacteriana foi realizada levando em consideração as características morfológicas, tintoriais e bioquímicas, segundo Carter \& Cole (1990) e Quinn et al. (1994). As bactérias isoladas foram submetidas à prova de sensibilidade aos antimicrobianos pela técnica de difusão do disco segundo Oplustil et al. (2004).

Imuno-histoquímica. Imuno-histoquímica para Mycoplasma hyopneumoniae foi realizada em pulmões de 25 animais (uma amostra de cada animal) de acordo com Lorenzo et al. (2006). No exame utilizaram-se a técnica da Streptavidina marcada com Peroxidase (Kit LSAB, Dako), recuperação antigênica com Microondas e tripsina, soro primário monoclonal contra a proteína P36 do M. hyopneumoniae, PBS pH 7.4 nas lavagens, revelação da reação com amino-etil-carbazol (AEC) e contracoloração com hematoxilina de Meyer.

PCR. Amostras do tecido pulmonar de quatro javalis foram coletados e submetidos à técnica de PCR para $M$. hyopneumoniae de acordo com Artiushin et al. (1993). 


\section{RESULTADOS}

\section{Sinais clínicos}

Os sinais clínicos foram essencialmente os mesmos em todos os animais. Apresentavam atraso no desenvolvimento corporal, diminuição do apetite, letargia, tosse e dificuldade respiratória, especialmente quando movimentados. Principalmente nos animais com evolução aguda do quadro, constatou-se elevação da temperatura para $40^{\circ} \mathrm{C}$, em média. $\mathrm{Na}$ auscultação pulmonar, havia crepitações e estertores de intensidade moderada. Dos 63 animais necropsiados com lesões pulmonares, 20 tinham lesões concomitantes de enterite fibrinonecrótica acentuada no intestino grosso. Essas lesões eram similares às observadas em outros vinte javalis da mesma granja e diagnosticadas como salmonelose entérica. Destes, a bactéria Salmonella enterica subesp. enterica sorovariedade Saintpaul foi isolada e tipificada em dois animais, de acordo com o relato de Ecco et al. (2006).

\section{Patologia}

As alterações macroscópicas nos pulmões analisados eram típicas de broncopneumonia lobular. As descrições são referentes à cor, consistência e distribuição das lesões. Os animais (35/63) tinham os lobos craniais, acessório e na maioria das vezes o terço ventral dos lobos
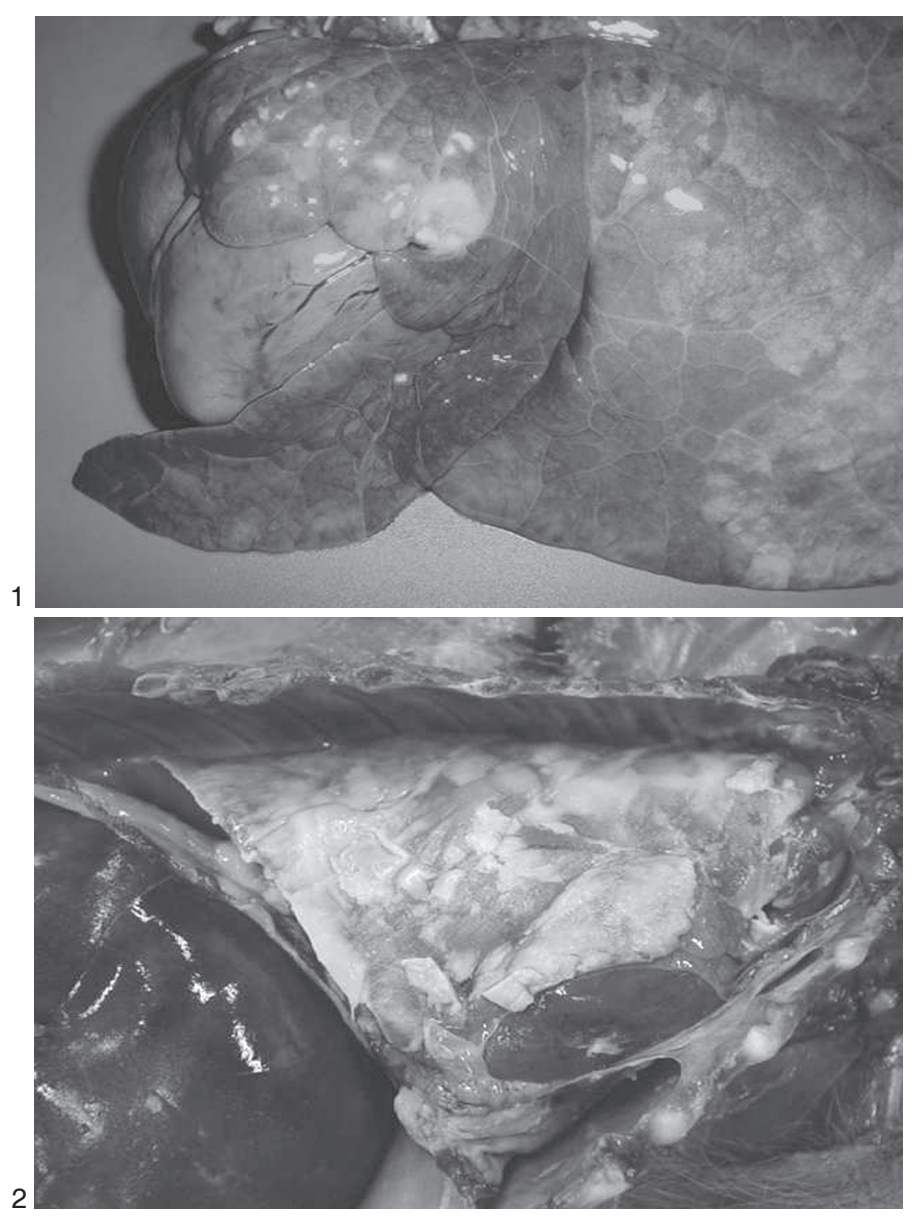

caudais macroscopicamente vermelho-escuros e consolidados. Com relação à distribuição das lesões nestes animais, a consolidação dos lobos craniais era difusa ou ocupava cerca de $60-80 \%$ da extensão. Já, a consolidação dos lobos caudais era crânio-ventral e ocupava de $30-50 \%$ de extensão. Lobos vermelho-escuros e com pequenas áreas $(2-50 \mathrm{~mm})$ brancas, secas e proeminentes foram observadas em 12 animais (Fig.1).

Pleurite e pericardite fibrinosa aguda (Fig.2) foram observados em 4 animais. Em 12 javalis, incluindo 4 animais com 8 meses de idade, os lobos eram difusamente acinzentados ou branco-amarelados (Fig.3). Outros 16 javalis apresentavam lóbulos vermelho-escuros intercalados por lóbulos cinza (padrão mosaico). A consistência era moderada a acentuadamente firmes. Nas regiões limites com as áreas firmes, os lóbulos estavam com atelectasia e/ou hiperinflados. Na maioria dos pulmões observou-se exsudato mucopurulento na luz dos brônquios e fluindo do parênquima. Os linfonodos pulmonares estavam aumentados de volume.

Os achados histopatológicos nas amostras coletadas de animais em fase aguda (13/63) foram necrose do epitélio bronquiolar e de pneumócitos, com acúmulo de células desprendidas e necróticas no lúmen, algumas sendo fagocitadas por macrófagos. A infiltração de neutrófilos e macrófagos foi evidente na luz dos brônquios, bronquíolos e no lúmen dos alvéolos adjacentes caracterizando uma broncopneumonia purulenta aguda. Nos pulmões dos javalis em fase subaguda (37/63), as lesões consistiam de broncopneumonia purulenta e histiocitária acentuada, necrose multifocal e infiltrado linfoplasmocitário

Fig.1. Pulmão do Javali 19. Lobos craniais e parte ventral do lobo caudal consolidados e com áreas brancas necróticas.

Fig.2. Cavidade Torácica do Javali 1. Os pulmões estão recobertos por membranas de fibrina.

Fig.3. Pulmão do Javali 23. O lobo pulmonar cranial e a porção médio-ventral do lobo caudal esquerdo estão difusamente branco-acinzentados.

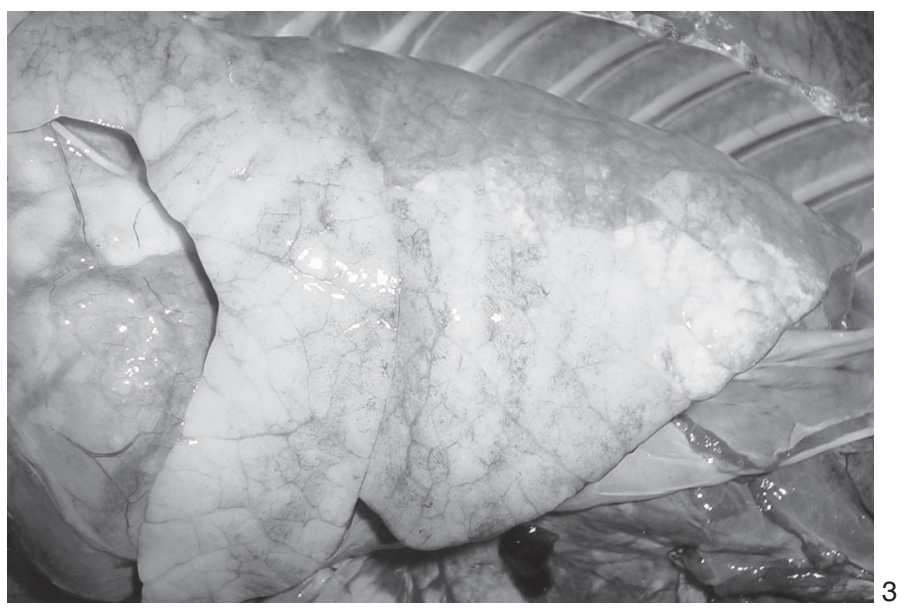






Fig.4. Hiperplasia do tecido linfóide peribronquiolar (seta), infiltrado inflamatório no lúmen bronquiolar e nos alvéolos adjacentes $\left(^{*}\right)$, no pulmão do Javali 18. HE, obj.10x.

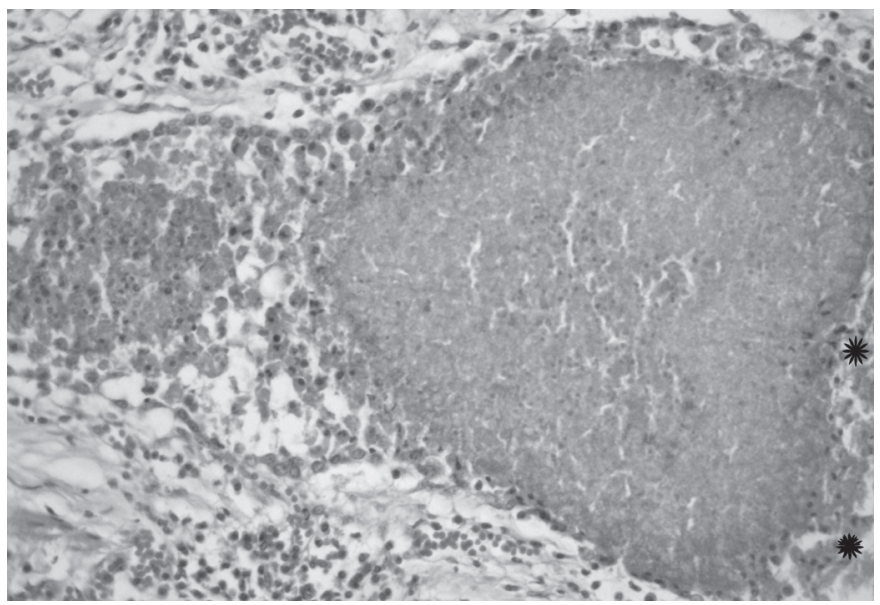

Fig.5. Bronquiectasia no pulmão do Javali 45. Bronquíolo com acentuada necrose da parede $\left(^{\star}\right)$, ectasia e lúmen contendo material necrótico e colônias bacterianas. HE, obj.20x.

perivascular e peribronquiolar. Na sua maioria, as lesões agudas e subagudas foram observadas em animais mais jovens, com até 70 dias de idade. Nas amostras provenientes de animais em fase crônica ou crônica-ativa (13/ $63)$, caracterizadas macroscopicamente pela cor brancoamarelada ou cinza, haviam ainda numerosos neutrófilos, mas acentuou-se a infiltração por macrófagos espumosos intra-alveolares e a fibroplasia dos septos alveolares. Pode-se observar, também, proliferação de tecido angiofibroblástico intersticial e peribronquial multifocal, além de hipertrofia e hiperplasia de pneumócitos tipo II. Em alguns animais havia também hiperplasia dos folículos linfóides peribronquiais (BALT) (Fig.4) e na maioria dos animais havia infiltração por linfócitos e plasmócitos perivasculares e peribronquiais. Áreas multifocais de seqüestro, necrose de liquefação e bronquiectasia necrótica (Fig.5) associadas a colônias bacterianas foram observadas em vários animais. Além dessas alterações, em quatro animais havia tonsilite necropurulenta.
De 7 javalis necropsiados no mês de janeiro de 2003, cinco tinham lesões compatíveis com rinite atrófica progressiva dos suínos. Clinicamente apresentaram deformações dos focinhos de intensidade leve, tinham espirros, tosse seca e um notável atraso no desenvolvimento corporal. À necropsia, constatou-se que em três javalis as lesões eram iniciais, com aumento moderado do lúmen de ambos os meatos, diminuição bilateral na espessura e tamanho dos cornetos e apenas um com leve desvio lateral direito do septo nasal. Nos outros dois javalis a diminuição bilateral das conchas nasais e o aumento dos meatos foram acentuados. Histologicamente, as alterações em todos os animais eram essencialmente as mesmas, diferindo apenas na intensidade e consistiam em perda do epitélio ciliar e havia somente remanescentes de trabéculas ósseas com poucos osteoblastos e raros osteoblastos. Os turbinados nasais, em grande extensão, eram constituídos por tecido conjuntivo fibroso. Lamentavelmente, exames bacteriológicos da cavidade nasal não foram realizados. Dos cinco javalis com rinite atrófica progressiva, quatro tinham lesões de broncopneumonia crônica. Nos quatro meses anteriores a janeiro de 2003 , foram necropsiados 70 animais da própria granja, sem que houvessem achados patológicos de rinite atrófica. Após dois meses da introdução de novos javalis (reprodutores e filhotes provenientes de outro criatório), observou-se espirros sugestivos de rinite nos animais da granja que estavam na faixa etária de 3-4 meses.

\section{Bacteriologia}

Das 27 amostras de pulmões submetidas à cultura bacteriana, 20 apresentaram crescimento significativo (Quadro 1). Cada amostra correspondia a um animal.

Antibiogramas foram realizados para os isolados pulmonares de Bordetella bronchiseptica e Rhodococcus equi. B. bronchiseptica foi sensível ao ceftiofur, cotrimazina + espiramicina, enrofloxacina, florfenicol, colistina, cloranfenicol, gentamicina e neomicina e resistente à amoxicilina, apramicina, norfloxacina, penicilina, sulfazotrim, ampicili-

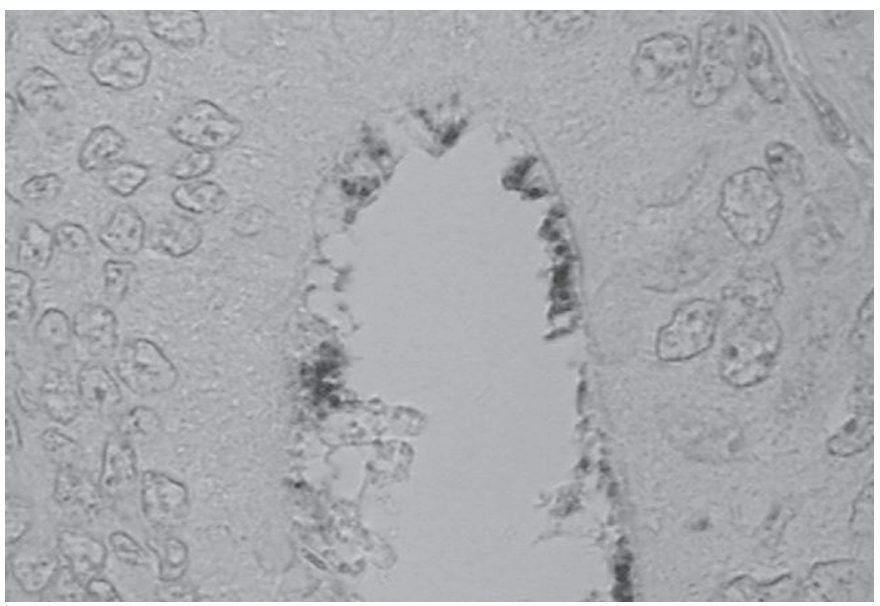

Fig.6. Pulmão de javali com broncopneumonia. Notar marcação positiva para Mycoplasma hyopneumoniae nos cílios do epitélio bronquial. Imuno-histoquímica, obj.40x. 
Quadro 1. Idade e resultados do isolamento bacteriológico e da imuno-histoquímica realizados nos javalis necropsiados no período de julho de 2002 a janeiro de 2003

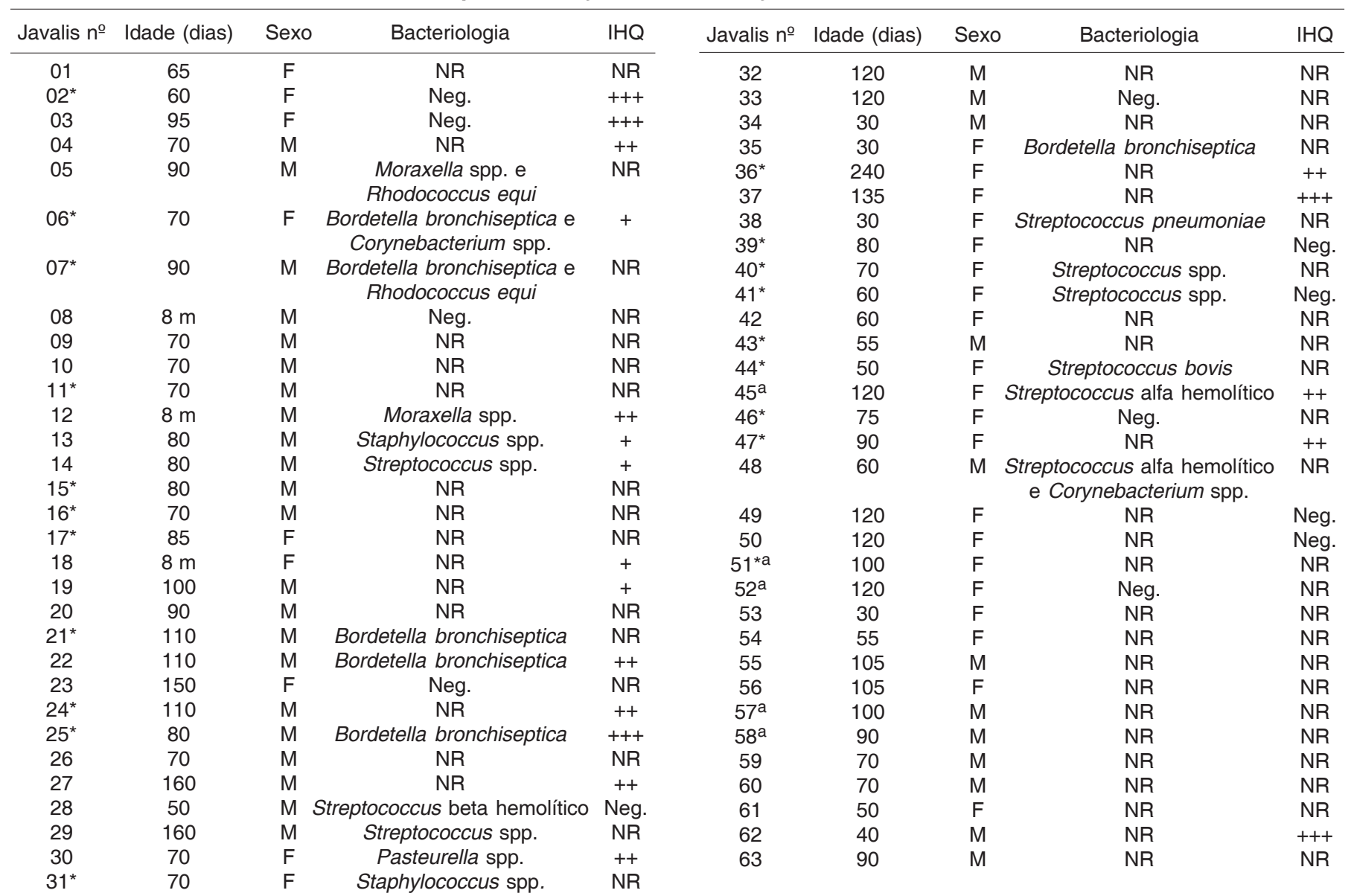

$\mathrm{NR}=$ Exames não realizados.

* Javalis que apresentavam concomitantemente lesões de salmonelose entérica no intestino grosso.

a Javalis que apresentavam lesões compatíveis com rinite atrófica.

Neg. = Negativo para o antígeno de Mycoplasma hyopneumoniae e para o isolamento bacteriano; + Positivo com escassa quantidade de antígeno de M. hyopneumoniae; ++ Positivo com moderada quantidade de antígeno de M. hyopneumoniae; +++ Positivo com acentuada quantidade de antígeno de M. hyopneumoniae.

Javalis 19, 22, 24, 36, 44 e 47 foram positivos para M. hyopneumoniae somente no epitélio descamado dos brônquios.

na, estreptomicina e tetraciclina. Rhodococcus equi foi sensível ao cloranfenicol, enrofloxacina, eritromicina, estreptomicina, gentamicina, neomicina, rifampicina, sulfazotrin e tetraciclina e resistente à ampicilina e penicilina.

\section{Imuno-histoquímica e PCR}

Dentre as amostras de 25 animais testados pela imunohistoquímica para Mycoplasma hyopneumoniae, marcação positiva (Fig.6) para este patógeno foi observada em 19 amostras (Quadro 1). PCR (Polymerase Chain Reaction) para $M$. hyopneumoniae foi realizada em quatro destes animais, sendo todos positivos.

\section{DISCUSSÃO}

Os sinais clínicos, lesões macroscópicas e histopatológicas foram típicas de broncopneumonia lobular em todos os javalis desse estudo. A detecção de DNA pela PCR e a demonstração da bactéria Mycoplasma hyopneumoni- ae pela imuno-histoquímica confirmaram a presença do patógeno nesses animais e envolvimento no surto de broncopneumonia desse criatório.

A maioria dos javalis adoeceu e morreu com 30-100 dias de idade, sendo o maior número com 70-80 dias. Somente quatro javalis desenvolveram graves sinais respiratórios e morreram aos 8 meses de idade. O período de 55-60 dias era o período considerado crítico na granja, pois coincidia com a idade de desmame. Em suínos, $M$. hyopneumoniae já foi detectado no trato respiratório inferior em suínos na maternidade, cujas mães eram sorologicamente positivas para este agente. Isto indica que os problemas respiratórios associados com este agente podem começar precocemente em uma granja em conseqüência da transmissão horizontal (Fano et al. 2005, Sibila et al. 2007). Trabalhos experimentais mostram que os sinais clínicos como tosse pode iniciar no período de 28 a 35 dias pós-infecção (Fano et al. 2005). 
A alteração macroscópica característica da pneumonia por micoplasma em suínos é a consolidação lobular confluente das regiões crânio-ventrais dos pulmões. As porções consolidadas variam de vermelho-escuro a rosa acinzentado ou cinza após vários meses de lesão. (Dungworth 1993). Estudos experimentais indicam que as lesões macroscópicas típicas não ocorrem até duas a quatro semanas após a infecção (Caswell \& Williams 2007).

Nos javalis desse estudo, havia diferenças no aspecto e na distribuição das lesões pulmonares. Alterações caracterizadas por lobos vermelho-escuros e firmes crânioventralmente indicaram a fase aguda ou subaguda das lesões. Por outro lado, lobos acinzentados ou com áreas brancas e secas caracterizam alterações proliferativas (fibroplasia) e de necrose de liquefação, respectivamente. Em suínos, broncopneumonia exsudativa acentuada e necrose indicam infecção por bactérias oportunistas de forma isolada ou em associação (Dungworth 1993, Caswell \& Williams 2007).

A mortalidade associada à infecção por M. hyopneumoniae ocorre principalmente quando há infecção bacteriana secundária. Lesões de broncopneumonia com necrose ou abscessos indicam infecção bacteriana secundária. Pasteurella multocida é o agente secundário mais comum em suínos (Ross 1999, Calsamiglia et al. 2000). Patógenos como Arcanobacterium pyogenes, Haemophilus spp., Streptococcus spp., Staphylococcus spp., Klebsiella spp. e Bordetella bronchiseptica podem estar envolvidos sozinhos ou em combinação em estudos da doença natural em suínos (Dungworth 1993, Ross 1999, Know et al. 2002). Streptococcus suis causa broncopneumonia supurativa como infecção única ou em combinação com P. multocida (Reams et al. 1994, Vasconcelos et al. 1994).

Nos javalis estudados, as principais bactérias isoladas foram Bordetella bronchiseptica e Streptococcus spp. Foi encontrada, também, associação das bactérias Streptococcus spp., Moraxella spp. e B. bronchiseptica com $M$. hyopneumoniae, e associação das bactérias $B$. bronchiseptica com Corynebacterium spp. e $B$. bronchiseptica com Rhodococcus equi. A falta de crescimento bacteriano em várias amostras desses animais possivelmente foi determinada pela antibioticoterapia e conseqüente inibição do crescimento bacteriano nos meios de cultivo.

$M$. hyopneumoniae também pode causar pleurite fibrinosa ou serofibrinosa e inflamação em outras superfícies serosas em suínos (Caswell \& Williams 2007). Quando a pleurite está presente, entretanto, é mais provável estar associada com P. multocida ou Haemophilus spp. (Dungworth 1993). Streptococcus suis e Haemophilus parasuis são relacionados à pleurite e peritonite fibrinosa ou fibrinopurulenta em suínos (Reams et al. 1994). Dos javalis estudados com pleurite e pericardite, em um animal de 30 dias foi isolado $B$. bronchiseptica e em um animal de 60 dias foi isolado Streptococcus alfa hemolítico, sendo que este animal também apresentou, forte positividade na imuno-histoquímica para $M$. hyopneumoniae.

Lesões histológicas causadas unicamente por M. hyopneumoniae possuem padrão histomorfológico de pneumonia broncointersticial, sendo caracterizadas no estágio agudo por perda dos cílios, esfoliação das células epiteliais, acumulação de neutrófilos e macrófagos na luz dos brônquios e bronquíolos e nos alvéolos adjacentes (Dungworth 1993, Kwon et al. 2002). Estas alterações coincidem com a patogênese descrita na infecção por $M$. hyopneumoniae. No estágio inicial da infecção, $M$. hyopneumoniae coloniza a superfície das células epiteliais da traquéia, brônquios e bronquíolos, estando em grande número aderido aos cílios do epitélio (Ross 1999), mas não no citoplasma dessas células. Esta associação leva a progressiva perda de cílios, descamação do epitélio e desenvolvimento de pneumonia (Know et al. 2002). Irigoyen et al. (1998) relataram que micoplasmas não foram observados ultra-estruturalmente nos pneumócitos, possivelmente relacionado à atividade dos fagócitos intraalveolares. Know et al. (2002) tiveram positividade na hibridização in situ para pneumócitos do tipo I e para macrófagos alveolares e intersticiais apenas em alguns pulmões, relacionando essa localização a possíveis cepas diferentes de Mycoplasma. Strait et al. (2008) utilizaram diferentes técnicas de PCR e verificaram que há diversidade genética entre os isolados de $M$. hyopneumoniae. Nas amostras pulmonares dos javalis desse estudo em que foi realizada a imuno-histoquímica, $M$. hyopneumoniae foi demonstrado na borda luminal do epitélio dos brônquios e bronquíolos e também no citoplasma de fagócitos no lúmen.

Sarradel et al. (2003) e Rodríguez et al. (2004) sugerem que as lesões alveolares podem não ocorrer devido ao efeito patogênico direto deste agente, mas secundariamente à produção de citocinas pró-inflamatórias tais como fator de necrose tumoral (TNF), interleucina 1 (IL1), IL-6 e IL-8. Estas citocinas estimulam a infiltração e a ativação das células inflamatórias (neutrófilos e macrófagos) nos espaços bronco-alveolares pelo persistente efeito quimiotático, determinando a lesão tecidual

Nos estágios crônicos da pneumonia micoplásmica, ocorre extensiva hiperplasia do tecido linfóide associado aos brônquios e bronquíolos e espessamento dos septos alveolares (Sarradel et al. 2003). A ativação linfóide também ocorre pelo efeito das citocinas (Rodríguez et al. 2004). Em alguns pulmões desses javalis a hiperplasia linfóide foi observada associada à broncopneumonia supurativa e infiltrado linfocitário perivascular peribronquiolar.

Alterações de necrose, associada à broncopneumonia em suínos foram encontradas por Brockmeier et al. (2002), após reprodução experimental em leitões com a toxina dermonecrótica da Bordetella bronchiseptica. Liljegren et al. (2003) identificaram essas alterações em suínos, associada à infecção por Staphylococcus aureus. Em vários javalis deste estudo os focos de necrose continham numerosas colônias bacterianas. Alguns desses 
focos estavam envoltos por neutrófilos caracterizando áreas de seqüestro pulmonar, encontrados nos casos de evolução aguda. Em outros pulmões, as áreas de necrose de liquefação eram bem circunscritas, não tinham colônias bacterianas visíveis e estavam envoltas por macrófagos e fibroplasia, observadas nos casos de evolução crônica.

Em dois animais, foram observados brônquios e bronquíolos com ectasia e preenchidos por exsudato, material necrótico e colônias bacterianas. Macroscopicamente, nestes casos, não foi possível distinguir entre as áreas de necrose/abscessos e os bronquíolos ectásicos preenchidos por material necrótico. A ocorrência de ectasia bronquiolar foi relatada em pulmões de suínos de abate e associadas à infecção por Staphylococcus aureus e Arcanobacterium pyogenes (Liljegren et al. 2003). Em um dos javalis desse estudo com bronquiectasia foi isolada a bactéria Streptococcus spp. A patogênese que determina a ectasia bronquiolar geralmente envolve bronquite crônica com destruição das paredes. Ocorre dilatação permanente de um brônquio ou bronquíolo como resultado do acúmulo de exsudato no lúmen e ruptura parcial das paredes. A destruição das paredes ocorre, em parte, quando enzimas proteolíticas liberadas das células fagocitárias durante a inflamação crônica degradam e enfraquecem os tecidos que compõem a parede e ajudam a manter o diâmetro normal da via aérea (López 1998).

A detecção de $M$. hyopneumoniae do tecido pulmonar pela PCR é amplamente utilizada (Maes et al. 2008). A técnica de PCR é um método de amplificação que pode detectar um pequeno número de $M$. hyopneumoniae nas células bronquiolares, sendo a técnica de maior sensibilidade (Cai et al. 2007). No entanto, sua detecção deve ser associada com as lesões para o diagnóstico de broncopneumonia por esse agente. Trabalhos experimentais que avaliaram a duração da doença indicam que os sinais clínicos e as lesões podem desaparecer em um período de 12-14 semanas após a exposição pura por $M$. hyopneumoniae, mas, o agente permanece e pode ser detectado pelo cultivo e PCR (Maes et al. 2008).

Nem a vacinação, nem a medicação preventiva podem prevenir a infecção e aderência de $M$. hyopneumoniae nas células ciliadas do trato respiratório. Em casos de níveis elevados de infecção ou em rebanhos com instalações e manejo precário, o uso de antimicrobianos pode ser necessário para melhores resultados na vacinação e para a melhora clínica e das lesões (Maes et al. 2008).

O quadro clínico e macroscópico em vários javalis foi semelhante aos relatados nos suínos domésticos acometidos por pneumonia enzoótica. No entanto, as lesões de broncopneumonia lobular exsudativa são similares nas várias infecções bacterianas (Reams et al. 1994), sendo fundamental o cultivo bacteriano e a análise histopatológica para o diagnóstico diferencial.

A exposição constante dos javalis a poeira possivelmente contribuiu para o desencadeamento de infecções e o estabelecimento de broncopneumonia exsudativa acentuada. A poeira em granjas de suínos contém grande número de bactérias Gram-positivas e Gram-negativas que podem entrar em suspensão e determinar graves infecções respiratórias (Wang et al. 1997).

Contato entre javalis e o suíno doméstico deveria ser evitado. O contato possibilita que agentes patogênicos do suíno sejam transmitidos e levem a elevada mortalidade como ocorreu nesse criatório. A condição inversa também pode ocorrer já que javalis são reservatórios de patógenos potenciais como o vírus da doença da doença de Auszjesky (Cunha et al. 2006) e de Mycobaterium bovis causador da tuberculose (Martin-Hernando et al. 2007).

\section{CONCLUSÃO}

Acreditamos que os javalis, quando retirados de seu ambiente natural e submetidos a um ambiente sem o devido conforto e higiene, são tão ou mais suscetíveis às infecções que o suíno doméstico. Esse é o primeiro relato da ocorrência da infecção por Mycoplasma hyopneumoniae e desencadeamento de broncopneumonia bacteriana em criatórios comerciais de javalis.

\section{REFERÊNCIAS}

Brockmeier S.L., Register K.B., Magyar T., Lax A.J., Pullinger G.D. \& Kunkle R.A. 2002. Role of the dermonecrotic toxin of Bordetella bronchyseptica in the pathogenesis of respiratory disease in swine. Infect. Immun. 70:481-490.

Cai H.Y., Van Dreumel T., McEwen B., Hornby G., Bell-Rogers P., McRaild P., Josephson G. \& Maxie G. 2007. Application and field validation of a PCR assay for the detection of Mycoplasma hyopneumoniae from swine lug tissue samples. J. Vet. Diagn. Invest. 19:91-95.

Carter G.R. \& Cole J.R. 1990. Diagnostic Procedures in Veterinary Bacteriology and Mycology. 5th ed. Academic Press, San Diego. 620p.

Caswell J.L. \& Williams K.J. 2007. Respiratory system, p.523-653. In: Maxie M.G. (Ed.), Jubb, Kennedy and Palmer's Pathology of Domestic Animals. Vol.2. Elsevier Saunders, Toronto.

Cunha E.M.S., Nassar A.F., Lara M.C.C.S.H., Bersano J.G., Villalobos E.M.C. \& Oliveira J.C.F. 2006. Anticorpos contra o vírus da doença de Aujeszky em javalis no estado de São Paulo. Arq. Bras. Med. Vet. Zootec. 58:462-466.

Dungworth D.L. 1993. The respiratory system, p.539-698. In: Jubb K.V.F., Kennedy P.C. \& Palmer N. (Eds), Pathology of Domestic Animals. Vol.2. Academic Press, San Diego.

Ecco R., Guedes R.M.C., Túry E. \& Perecmanis S. 2006. Outbreak of enterocolitic salmonellosis on a wild pig farm. Vet. Rec. 158:242-243.

Ellis J., Spinato M., Yong C., West K., McNeilly F., Meehan B., Seamus K., Clark E., Krakowka S. \& Allan G. 2003. Porcine circovirus 2associated disease in Eurasian wild boar. J. Vet. Diagn. Invest. 15:364368.

Escobar J., Van Alstine W.G., Baker D.H. \& Johnson R.W. 2002. Growth performance and whole-body composition of pigs experimentally infected with Mycoplasma hyopneumoniae. J. Anim. Sci. 80:384-391.

Fano E., Pijoan C. \& Dee S. 2005. Dynamics and persistence of Mycoplasma hyopneumoniae infection in pigs. Can. J. Vet. Res. 69:223-228.

Irigoyen L.F., Van Alstine W., Turek J. \& Clark L.K. 1998. Ultrastructural observation of the airways of recovered and susceptible pigs after inoculation with Mycoplasma hyopneumoniae. Pesq. Vet. Bras. 18:17. 
Kwon D., Choi C. \& Chae C. 2002. Chronologic localization of Mycoplasma hyopneumoniae in experimentally infected pigs. Vet. Pathol. 39:584-587.

Liljegren C.H., Aalbaek B., Nielsen O.L. \& Jensen H.E. 2003. Some new aspects of the pathology, pathogenesis and aetiology of disseminated lung lesions in slaughter pigs. APMIS 111:531-538.

López A. 1998. Sistema respiratório, p.132-193. In: Carlton W.W. \& McGavin M.D. (Eds), Patologia Veterinária Especial de Thomson (Tradução de Claudio S.L. Barros). $2^{2}$ ed. Artmed, Porto Alegre.

Lorenzo H., Quesada O., Assunção P., Castro A. \& Rodríguez F. 2006. Cytokine expression in porcine lungs experimentally infected with Mycoplasma hyopneumoniae. Vet. Immun. Immunopathol. 109:199207.

Maes D., Segales J., Meyns T., Sibila M., Pieters M. \& Haesebrouck, F. 2008. Control of Mycoplasma hyopneumoniae infections in pigs: A review. Vet. Microbiol. 126:297-309.

Martin-Hernando M.P., Höfle U., Vicente J., Ruiz-Fons F., Vidal D., Barral M., Garrido J.M., La Funte F. \& Gortazar C. 2007. Lesions associated with Mycobaterium tuberculosis complex infection in the European wild boar. Tuberculosis 87:360-367.

Oplustil C.P., Zoccoli C.M., Tobouti N.R. \& Sinto S.I. 2004. Procedimentos Básicos em Microbiologia Clínica. $2^{2}$ ed. Sarvier, São Paulo. $304 p$.

Quinn P.J., Carter M.E., Markey B. \& Carter G.R. 1994. Clinical Veterinary Microbiology. Mosby, London. 648p.

Reams R.Y., Glickman L.T., Harrington D.D., Thacker H.L. \& Bowersock T.L. 1994. Streptococus suis infection in swine: A retrospective study of 256 cases. Part II. Clinical signs, gross and microscopic lesions, and coexisting microorganisms. J. Vet. Diagn. Invest. 6:326-334.

Rodríguez F., Ramírez G.A., Sarradel J., Andrada M. \& Lorenzo H.
2004. Immunohistochemical labelling of cytokines in lung lesions of pigs naturally infected with Mycoplasma hyopneumoniae. J. Comp. Pathol. 130:306-312.

Ross R.F. 1999. Mycoplasmal diseases, p.495-509. In: Straw B.E., Mengeling W.L., Taylor D.J. \& Allaire S.D. (Eds), Diseases of Swine. 8th ed. lowa State University, Ames.

Sarradel J., Andrada M., Ramírez A.S., Fernández J.C., GómezVillamandos A.J., Lorenzo H., Herráez P. \& Rodríguez F. 2003. A morphologic and immunohistochemical study of the bronchusassociated lymphoid tissue of pigs naturally infected with Mycoplasma hyopneumoniae. Vet. Pathol. 40:395-404.

Sibila M., Nofrarías M., López-Soria S., Segalés J., Riera, P., Llopart, D. \& Calsamiglia M. 2007. Exploratory field study on Mycoplasma hyopneumoniae infection in suckling pigs. Vet. Microbiol. 121:352356.

Taylor D.J. 2006. Actinobacillus suis, p.827-829. In: Straw B.E., Zimmerman J.J., D'Allaire S. \& Taylor D.J. (Eds), Diseases of Swine. 9th ed. Blackwell Publishing, Ames.

Thacker E.L. 2004. Diagnostic of Mycoplasma hyopneumoniae. Anim. Hlth Res. Rev. 5:317-320.

Vasconcelos D., Middleton D.M. \& Chirino-Trejo J.M. 1994. Lesions caused by natural infection with Streptococcus suis type 9 in weaned pigs. J. Vet. Diagn. Invest. 6:335-341.

Vicente J., Leon-Vizcaíno L., Gortazar C., José Cubero M., González M. \& Martín-Atance P. 2002. Antibodies to selected viral and bacterial pathogens in European wild boars from south-central Spain. J. Wildl. Dis. 38:649-652.

Wang Z., Larsson K., Palmberg L., Malmberg P. \& Larsson L. 1997. Inhalation of swine dust induces cytokine release in the upper and lower airways. Eur. Respir. J. 10:381-387. 